\title{
Interpretive Structural Model of Trust Factors in Construction Virtual Project Teams
}

\begin{abstract}
Purpose

Organisational dependence on virtual project teams (VPTs) is growing dramatically due to the substantial benefits they offer, such as efficiently achieving objectives and improving organisational performance. One of the major issues that influence the effectiveness of VPTs is trust building. The study aims to determine the key factors of trust in VPTs and design a model by identifying the interrelationships among the trust factors.

Design/methodology/approach

Focus group discussion was employed to gather data on factors affecting trust in VPTs and their interrelationships. Interpretive Structural Modelling (ISM) was used to establish the relationship among the factors. MICMAC analysis was conducted to identify the driving power and the dependence power towards effective VPTs in the construction sector.
\end{abstract}

Findings

The finding revealed that 'characteristics of team members' (such as ability, integrity, benevolence, competence, reliability and professionalism) is the most significant factor for building trust in virtual team members. Some factors were further identified as having high driving power, while others were defined as having high dependence variables.

Practical implications

The findings will assist construction managers and practitioners dealing with VPTs identify the factors influencing trust among team members. Taking cognisance of the factors that influence trust will enable them to design more effective virtual team arrangements.

Originality/value

As the first research of its kind using ISM technique, the study offers insights into interrelationships between trust factors in the construction VPTs. It provides guides for construction managers on the effective management of trustworthy VPTs.

Keyword: Interpretive Structural Modelling, virtual project teams, focus group, trust, Middle East. 


\section{Introduction}

The Fourth Industrial Revolution brought about major changes in the field of organisational desi ${ }_{\circ}$ n. particularly in the way work is planned, organised, and carried out (Lukić \& Vračar, 2018). The changes are supported by the continuous development of modern information and communication technologies (ICT) (Luo et al., 2018). One of the key trends extensively accepted by several organisations globally is the development of VPTs, which allow participants to work from remote areas regardless of time zone, nation, or culture and cooperate utilising various ICT. Irrespective of the industry, many organisations have created team-based organisational structures, which have given them the required flexibility, decentralised decision-making, increased cooperation, and knowledge transfer among employees. (Tannenbaum et al., 2012). The benefits of VPTs in terms of cost savings, productivity growth, knowledge, skills, and flexibility are apparent and cannot be overlooked (Lukić \& Vračar, 2018). Despite these benefits, there are significant issues regarding creating a successful team among geographically distant employees (Lukić \& Vračar, 2018). One major challenge faced in VPTs is the low-level trust among team members (Choi \& Cho, 2019). Employees in VPTs have the same responsibilities and obligations as those in traditional teams whose members are physically present in the same location; however, virtual work alters how employees connect and communicate with one another. Hence, building maintaining trust is challenging. Many authors stressed the significance of trust as a crucial success component in VPTs (Brewer, 2015; Davidavičienè et al., 2020). Building trusting relationships is critical to virtual team performance because people who trust their peers are more likely to engage in risk-taking activities that allow for team great...ess.

To allow construction VPTs to perform at their best, one should consiaer the role played by the trust shared between virtual teammates. Delizonna (2017) revealed trat successful company executives and managers have remarked that there is no team without trust ice ent studies have also discovered that creating and sustaining trust in an organisation will be an ong the important organisational issues of the future, as businesses will be assessed on their trist and fairness (Brown et al., 2017; Kaur, 2017). The shift caused by the COVID-19 pandemic ga: e a unique chance to examine teams throughout a moment of change, in which teams were comprilf $\mathrm{d}$ to consider their fundamental activities and how to execute them in the virtual environment (Whillans et al., 2021). Davidavičienè et al., (2020) affirmed a dearth of scientific studies 
attempting to comprehend the factors influencing virtual teams. Only in the United States and Europe have significant studies in this area been conducted. Such studies, however, has not been carried out in the Middle East, where specialised scientific answers are still necessary to increase the performance of VPTs. Because the Middle East is a multi-cultural region, it is critical to comprehend the phenomena of these cross-cultural virtual project teams. The Middle East is witnessing a construction boom, of which key projects such as the Qatar World Cup 2022 and the Dubai Expo, are significant drivers. There is a need to complete projects more quickly, which necessitates multitasking and improved collaboration among project teams. Also, the globalisation and changing customer needs in the Middle East required many construction companies to adopt VPTs for their business activities. However, the lack of trust among team members greatly affects the performance of construction VPTs. While past studies have established the relationship between trust and VPTs (Lukić \& Vračar, 2018; Hacker et al., 2019), there exists a gap in the literature concerning the influence of trust in VPTs in the construction sector, especially the Middle East (Kaur et al., 2019). This study aims at identifying trust factors and their relationship in the construction VPTs. The next section examines the literature on trust and the factors that influence VPTs. Next, we provide the methodo' ${ }^{1}{ }^{\top} \mathrm{y}$ followed with the ISM model development. Finally, we provide a discussion and conclusion vase $\_$on our findings.

\section{Literature review}

\section{Trust in VPTs}

The issue of trust is very important, particularly in the context of virtual teams because virtual team members are "geographically dispersed" and lack "shared social-context" and "face-to-face encounter". Trust is one of the most researched factors in the context $r$ : TTs (Turesky, et al.,

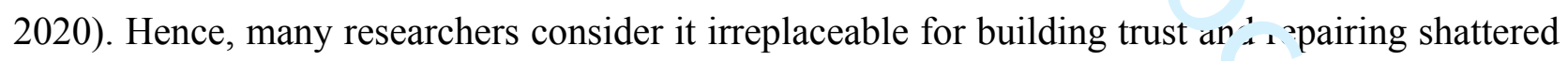
trust (Morrison-Smith \& Ruiz, 2020). As it is challenging to assess teammatf s' 1 ustworthiness without meeting them, it becomes a great challenge to develop trust within the team (GarroAbarca et al., 2021). Moreover, as many virtual teams’ lives are relatively limited, tru^ is required to be developed as quickly as possible as it hampers the information sharing among the if ams (Jarvenpaa et al., 1998). Evaristo (2003) suggested that one of the reasons people may not initially have trust in one another is the lack of knowledge about the rationale for past or present 
behaviours and intentions. Therefore it leads to the lack of willingness to risk vulnerability to an unknown situation. An absence of trust can lead to coordination problems and often results in conflicts. The development of trust ensures the reduction in process losses. Cunningham and MacGregor (2000) identified that trust results in the satisfaction and motivation of the team members. Teams that experienced low levels of trust among their members were less likely to share inform ${ }^{10}$ ? and ideas, which led to lower teams' performance (Schiller et al., 2014).

Trust is the most important factor that strongly impacts virtual team effectiveness (Bond-Barnard et al., 2018; Breuer e+ al. 2020; Choi \& Cho, 2019; Kildiushova, 2021). When people trust one another, they believe tha otl ers are willing and able to share their knowledge and develop an obligation to share (Staples \& Vebster, 2008). As a result, they will share knowledge not to violate that obligation, eventual'y lear'ng to virtual team effectiveness (Pangil \& Chan, 2014). It has been found that the failure of $V^{\prime}$ is is directly related to the difficulties of building trust and positive relationships across the three uoundaries of geographical distance, time zones, and cultural differences (Kimble, 2011). Trus in _reases the team members' motivation, which helps them share information among them, which is $\mathrm{n}$. Aed for greater performance of the virtual team. The issue of trust is very important, particularly in the context of VPTs because virtual project team members are geographically dispersed and lack shared social context and face-to-face encounters that many researchers consider as irreplaceable for building trust and repairing shattered trust (Jarvenpaa \& Leidner, 1999). From the comprehensive literature study, it has been found that some of the problems that multi-cultural virtual teams experience include: lack of trust among cross-cultural team members, time delays in replies, communications breakdowns due to cultural variances, unresolved conflicts among culturally different members, different holidays (Vinaja, 2003). The key findings reported by Vakola \& Wilson (2004) were the challenge of developing trust, leadership and managing virtual aspects of communication. Hosseini and Chileshe (2013) proposed that VPTs face particular challenges involving trust, communication, deadlines, and team cohesiveness. Therefore, trust is considered one of the biggest challenges in managing a virtual team. The following section presents factors affecting trust in VPTs.

\section{Factors affecting trust building in VPTs}

\section{Communication}


In virtual teams, effective communication and knowledge sharing results in the entire team's success. Effective communication in virtual teams is key to solid performance. It is the basis for developing high-performance work strategies and processes. Because of the distributed nature of their work unit, virtual team members have to rely heavily on information and communication technologies ( $\mathrm{Lu}, 2015)$. For communication to be effective, it is vital to select the right technology. As noted by Hulnick, "if technology is the foundation of the virtual business relationship, communication is the cement" (Hulnick, 2000, p. 33). Lack of effective communication results in time delays in sending feedback and a standard frame of reference for all members. It also leads to differences in interpretation of written text and assurance of participation from remote team members (Crampton, 2001). Thus, teams operating in the virtual environment face greater obstacles in the information exchange than traditional teams. Piccoli et al. (2004) analysed team member communication on the effectiveness of virtual teams and indicated that the most satisfied team members were in virtual teams with effective coordination and communication.

\section{Organizational Culture}

Organisational culture includes norms regarding the free flow of information, shared leadership, and cross-boundary collaboration. Organisations must provide the appropriate physical, financial and social support to the VPTs, including evaluation and compensation systems, training development programmes, and information systems that provide relevant, accurate and timely information. The organisational culture becomes the motivational factor for the VPTs to work together when they develop confidence in the internal operational issues (Kaur, 2017). In building virtual corporations, the managers must understand the diversity in international cultures so that understanding the issues of VPTs becomes easier (Davidavičienè et al., 2020). In addition, ineffective leadership and cultural differences (Davidavičienė et al., 2020; Morrison-Smith \& Ruiz, 2020) have negatively impacted communication effectiveness in virtual teams.

\section{Team Cohesiveness}

Cohesion is also an essential aspect of the virtual team. When compared to traditional team members, virtual team members generally report weaker bonding of teammates (Garro-Abarca et al., 2020; Warkentin et al., 1997). This is primarily because the team members rely significantly 
on the communication tools and technologies (Sproull \& Kiesler, 1986). Cohen and Bailey (1997) suggested that cohesion is a critical factor influencing the effectiveness of teams. They also concluded that a primary factor leading to team cohesion is the degree of trust among team members. Moreover, collaborative technologies hindered cohesion in virtual teams and resulted in less bondi.g ’mong team members (Morrison-Smith \& Ruiz, 2020; Warkentin et al., 1997).

\section{Diversity}

Virtual teams are a group of members who belong to different cultures and are experts in different fields. This kind of diversity or group heterogeneity results in increased conflict among team members and less effective performance of the team (Paul \& McDaniel, 2004). The reason for the usage of functionally diverse members in the team is external knowledge sharing. This results in increased performance because the technical knowledge and feedback push team members to work closer to common goals (Cummings, 2004). It is also noticed that team members who belong to the same culture or background tend to communicate with a common language and understanding, making it easier to establish workplace norms (Hosseini et al., 2016). But as virtual teams have mixed cultured people, the language barrier can become an obstacle in building trust within the virtual team.

\section{Conflict}

Zimmermann (2011) defined conflict as an expressed struggle between at least two interdependent parties who perceive incompatible goals, scarce rewards, and inte ference from the other party in achieving their goals. It can be viewed as a task, relationship and pror`ss conflict. Task conflict relates to perceived differences in views referring to tasks. Relationsnip conflict is concerned with

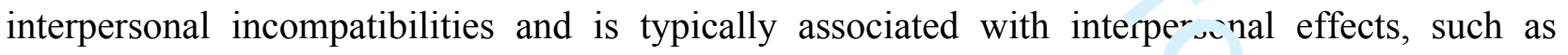
tension. Process conflict refers to disagreements about the ways to compluc ^ ${ }^{+}$ask. Relationship conflict has consistently been associated with process losses and decreased performance. It is observed that the frequency of occurrence of these kinds of conflicts results in the reduction of trust among team members.

\section{Team Members' characteristics}

Individual team member's characteristics, such as role and status, can impact communication patterns and, as a result, communication structure (Ahuja \& Carley, 1999). Virtual leaders, 
therefore, face additional challenges due to member characteristics as VPTs are dispersed work environments requiring leaders to handle heterogeneity in several dimensions (Taras et al., 2018). Heterogeneity refers to different demographic characteristics, cultural norms of team members, diversity of functional roles and the tenure of virtual team members. The team leaders should understand the expertise of the team members and distribute the functions to the team accordingly (Morrison-Smith \& Ruiz, 2020). Some individuals need guidance, and some are more dependent. The manager must lookout for specific individuals and play the role of mentor to them. This section dealt with the indicators affecting trust, which had been found through an extensive literature review. Through an empirical survey, we sought to explore elements of trust and their relationships in the constr icti $\mathrm{n}$ VPTs.

\section{Methodology}

This is a follow-up study on our previous research where six factors affecting the building of trust were identified through the statistical analysir $\approx$ f variables found through an extensive literature review. A similar method was employed in $\lrcorner$ re vvant study on global virtual teams (Rutz \& Tanner, 2016). From the previous study, six different factors that affect trust within VPTs include: 1) organisational culture of the company; 2) diversity of the team members; 3) degree of communication within the team; 4) team members' characteristics; 5) conflict within the team; 6) cohesion of the team. These factors have been discussed in the previous section.

\section{Data collection}

Semi-structured interviews of professionals from the construction sector in the Middle East was used for data collection in this study. Initially, a group of experts with the required knowledge, skills, and backgrounds were selected, and an invitation letter was sent o r $\cdots$ ticipate in the research. This group consist of experts from different areas with a wide-ran oin industry experts were interviewed to analyse the relationship between the various factors. Out of 10, four were project managers, and six were team members in their respective VPTs. These experts have a varied range of experience, starting from oil and gas sector to EPC projects. With average years of experience of 15 years, the participants are considered experts; hence, their 
submission is reliable. Their opinions on possible connections between contextualised trust factors in construction VPTs were solicited throughout the focus group discussion.

\section{Data analysis method}

ISM has been employed to analyse expert opinions based on various management techniques such as brainstorming and focus group discussion techniques in developing the contextual relationship between the various factors of trust (Kaur, 2017). ISM is a computer-assisted learning process that enables individuals or groups to map the complex relationships between the various factors involved in a complex situation (George \& Pramod, 2014). This study used the ISM to hierarchically and logically order expert opinions on relationships between trust factors in VPTs. ISM was used in a similar study by Ahuja (2017) in modelling the success factors of virtual teams. In ISM, I (Interpretive) stand for the outcome of judgment, S (Structural) stands for the extraction of the outcome of a set of variables, and M (Model) stands for the graphical representation of the specific relationship and overall structure (George \& Pramod, 2014).

\section{Steps involved in the development of model using ISM}

A stepwise procedure is to be adopted to develop a model of trust using ISM. The various steps involved in the ISM methodology are as follows (Rávi 'c Shankar, 2005):

Step 1: Identification of the elements that are relevant th th, problem or issue.

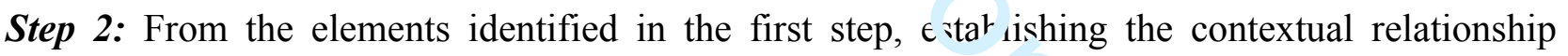
among them. This represents the relationship indicating wheth $\mathrm{r}$ or not one element leads to another.

Step 3: Developing a structural self-interaction matrix (SSIM) of sourcer which indicates a pairwise relationship between sources of the system under consideration.

Step 4: Developing a reachability matrix from the SSIM, and checking the r atrix for transitivity. Transitivity of the contextual relation is a basic assumption in ISM, which state : tiv $\mathrm{t}$ if element A is related to element $B$, and $B$ is related to $C$, then $A$ is necessarily related to $C_{\text {. }} T_{1} \circ S^{c}$. $M$ format is transformed in the format of the reachability matrix by transforming the information in each entry of the SSIM into $1 \mathrm{~s}$ and $0 \mathrm{~s}$ in the reachability matrix.

Step 5: The reachability matrix obtained in the fourth step is partitioned into different levels. 
Step 6: A directed graph is drawn, and the transitive links are removed based on the relationships given above in the reachability matrix.

Step 7: The resultant digraph is converted into an ISM by replacing variable nodes with statements.

Step 8: The ISM model developed in the seventh step is reviewed to check for conceptual inconsistency and make the necessary modifications.

\section{Analysis and results}

The interrelationships among different challenging factors of building trust among virtual project team members in the construction sector of the Middle East have been achieved through the ISM steps.

\section{Structural Self-Interaction Matrix (SSIM)}

For the purpose of this demonstration, the word "facilitate" is chosen to establish contextual relationships within the factors. This means that a particular factor facilitates another factor. On the basis of this, a contextual relationship between the factors is developed. The following four symbols were used to denote the relationship between the factors of trust in VPTs of the construction sector.

V: Factor $i$ facilitates factor $j$.

A: Factor $j$ facilitates factor $i$.

$\mathrm{X}$ : Factor $i$ and $j$ facilitates each other.

$\mathrm{O}$ : Factor $\mathrm{i}$ and $\mathrm{j}$ are unrelated.

The discussions with the experts helped in identifying the relationships between the identified factors of trust. The experts were asked to compare the column statement with ${ }^{\prime \prime} \backsim$ row statement for each cell and to choose a value from the set $(\mathrm{V}, \mathrm{A}, \mathrm{X}$, or O) to represent their per itption of the direct relationship between two factors at each time. On the basis of the contextual relationship between factors, the SSIM has been developed, as shown in Table 1. 


\section{Initial reachability matrix}

The initial reachability matrix is obtained from the SSIM format by transforming the information of each cell of SSIM into binary digits (i.e., 1s or 0s). This transformation has been done by substituting V, A, X, O by 1 and 0 as per the following rules (Obi et al., 2021).

- If the $(i, j)$ entry in the SSIM was $V$, then the $(i, j)$ input in the reachability matrix was 1 ;

- If the $(i, j)$ entry in the SSIM was A, then the $(i, j)$ input in the reachability matrix was 0 ;

- If the $(i, j)$ entry in the SSIM was $X$, then both the $(i, j)$ and the $(j, i)$ input in the reachability matrix were 1 ;

$\circ \quad$ If the $(i, j)$ entry in the SSIM was $O$, then the $(i, j)$ entry in the reachability matrix became 0 .

Following these rules, an initial reachability matrix is prepared along with SSIM, as shown in Table 1.

Table 1: SSIM and Initial Reachability Matrix

\begin{tabular}{|l|c|c|c|c|c|c|c|c|c|c|c|c|c|}
\hline Factors of Trust & & $\mathbf{1}$ & $\mathbf{2}$ & $\mathbf{3}$ & $\mathbf{4}$ & $\mathbf{5}$ & $\mathbf{6}$ & $\mathbf{1}$ & $\mathbf{2}$ & $\mathbf{3}$ & $\mathbf{4}$ & $\mathbf{5}$ & $\mathbf{6}$ \\
\hline \multicolumn{8}{|c|}{ SSIM } \\
\hline Organizational culture of the company & $\mathbf{1}$ & & $\mathrm{O}$ & $\mathrm{V}$ & $\mathrm{O}$ & $\mathrm{A}$ & $\mathrm{V}$ & 1 & 0 & 1 & 0 & 0 & 1 \\
\hline Diversity of the team members. & $\mathbf{2}$ & & & $\mathrm{V}$ & $\mathrm{A}$ & $\mathrm{V}$ & $\mathrm{A}$ & 0 & 1 & 1 & 0 & 1 & 0 \\
\hline Degree of communication within the team & $\mathbf{3}$ & & & $\mathrm{A}$ & $\mathrm{A}$ & $\mathrm{X}$ & 0 & 0 & 1 & 0 & 0 & 1 \\
\hline Team Members' characteristics & $\mathbf{4}$ & & & & $\mathrm{V}$ & $\mathrm{V}$ & 0 & 1 & 1 & 1 & 1 & 1 \\
\hline Conflict within the team & $\mathbf{5}$ & & & & & $\mathrm{X}$ & 1 & 0 & 1 & 0 & 1 & 1 \\
\hline Cohesion of the team & $\mathbf{6}$ & & & & & & 0 & 1 & 1 & 0 & 1 & 1 \\
\hline
\end{tabular}

\section{Final reachability matrix}

To get Final reachability matrix, the concept of transitivity is introduced, and some of the cells of the initial reachability matrix are filled in by inference. If a variable ' $i$ ' is related to ' $i$ ' and ' $j$ ' is related to ' $k$ ', then transitivity implies that variable ' $i$ ' is necessarily related to ' $k$ ' $T$ he final reachability matrix is developed after incorporating the transitivity concept as shown in Table 2 wherein entries marked * show the transitivity. 
Table 2: Final Reachability Matrix

\begin{tabular}{|l|c|c|c|c|c|c|c|c|}
\hline Factors of Trust & & & & & & $\mathbf{5}$ & $\mathbf{6}$ & Driving \\
\hline Organizational culture of the company & $\mathbf{1}$ & 1 & $1^{*}$ & 1 & 0 & $1^{*}$ & 1 & 5 \\
\hline Diversity of the team members. & $\mathbf{2}$ & $1^{*}$ & 1 & 1 & 0 & 1 & $1^{*}$ & 5 \\
\hline $\begin{array}{l}\text { Degree of communication within the } \\
\text { team. }\end{array}$ & $\mathbf{3}$ & 0 & $1^{*}$ & 1 & 0 & $1 *$ & 1 & 4 \\
\hline Team Members' characteristics & $\mathbf{4}$ & $1^{*}$ & 1 & 1 & 1 & 1 & 1 & 6 \\
\hline Conflict within the team & $\mathbf{5}$ & 1 & $1^{*}$ & 1 & 0 & 1 & 1 & 5 \\
\hline Cohesion of the team & $\mathbf{6}$ & $1^{*}$ & 1 & 1 & 0 & 1 & 1 & 5 \\
\hline Dependence Power & & 5 & 6 & 6 & 1 & 6 & 6 & $\mathbf{3 0}$ \\
\hline
\end{tabular}

In Table 2, the driving power of a particular source is the total number of factors (including itself) that it influences. The dependences are the total number of factors (including itself) that may help to influence its growth. These driving power and dependency values will be used to classify trust factors (MICMAC analysis).

\section{Level partitioning of the final reachability matrix}

After creating the final reachability matrix, a series of partitions are presented (Warfield, 1974) which are induced by the reachability matrix on the set and subset of different variables. From these partitions, one can identify many properties of the structural model. '? 1 . particular factor consists of the factor itself and the other factor it influences. T'it antecedent set consists of the factor itself and the other factor, which may influence it. Subs ecuently, the common factor of the reachability and antecedent sets form the intersection sct. When the reachability set and intersection set are the same, it is assigned as the top-level element in th. sM hierarchy. The top-level factors are those that will not lead the other factors above their ow.. ie il in the hierarchy. Once the top-level factor is identified, it is eliminated from further hierarchical analysis, and other top-level factors of the remaining sub-group are identified. This iteration is 
repeated till the levels of each issue are determined (Tables 3). The identified levels aid in building the digraph and the final model of ISM.

Table 3. Iter .ion 1 to 3 (Level Partitioning)

\begin{tabular}{|c|c|c|c|c|}
\hline \multicolumn{5}{|c|}{ Level Partitioning- Iteration 1} \\
\hline Factors of Trust & Reachability Set & Antecedent set & Intersection & Level \\
\hline $\begin{array}{l}\text { F1: Organizational culture of the } \\
\text { company }\end{array}$ & $1,2,3,5,6$ & $1,2,4,5,6$ & $1,2,5,6$ & \\
\hline F2: Diversity of the team members. & $1,2,3,5,6$ & $1,2,3,4,5,6$ & $1,2,3,5,6$ & I \\
\hline $\begin{array}{l}\text { F3: Degree of communication } \\
\text { within the team. }\end{array}$ & $2,3,5,6$ & $1,2,3,4,5,6$ & $2,3,5,6$ & I \\
\hline F4: Team Members' characteristics & $1,2,3,4,5,6$ & 4 & 4 & \\
\hline F5: Conflict within the team & $1,2,3,5,6$ & $1,2,3,4,5,6$ & $1,2,3,5,6$ & $\mathrm{I}$ \\
\hline F6: Cohesion of the team & $1,2,3,5,6$ & $1,2,3,4,5,6$ & $1,2,3,5,6$ & $\mathrm{I}$ \\
\hline \multicolumn{5}{|c|}{ Level Partitioning- Iteration 2} \\
\hline Factors of Trust & Reachability Set & Antecedent set & Intersection & Level \\
\hline $\begin{array}{l}\text { F1: Organizational culture of the } \\
\text { company }\end{array}$ & 1 & 1,4 & 1 & II \\
\hline F4: Team Members' characteristics & 1,4 & 4 & 4 & \\
\hline \multicolumn{5}{|c|}{ Level Partitioning- Iteration 3} \\
\hline Critical success factors & Reachability Set & Antecer'at set & Intersection & Level \\
\hline F4: Team Members' characteristics & 4 & 1 & 4 & III \\
\hline
\end{tabular}

The ISM model has the benefit of highlighting the most significant elements that must be carefully examined in order to accomplish effective trust development in VPTs. These critical elements are frequently found at the bottom of the ISM model. As a result, the factors at the top of the model will be dependent on the factors at the bottom to be realised.

\section{Building the ISM-based model}

First level factors are positioned at the top of the model and so on. From the final reachability matrix, the hierarchical model is generated. If a relationship exists between the two factors $\mathrm{i}$ and $\mathrm{j}$, it is depicted by an arrow pointing from $\mathrm{i}$ to $\mathrm{j}$. In this model, the top level factor is positioned at the top of the diagraph. The second level factor is placed at the second position and so on, until the 
bottom level factor is placed at the lowest position in the diagraph. Diagraph is finally converted into ISM after removing the transitive links, as shown in Figure 1.

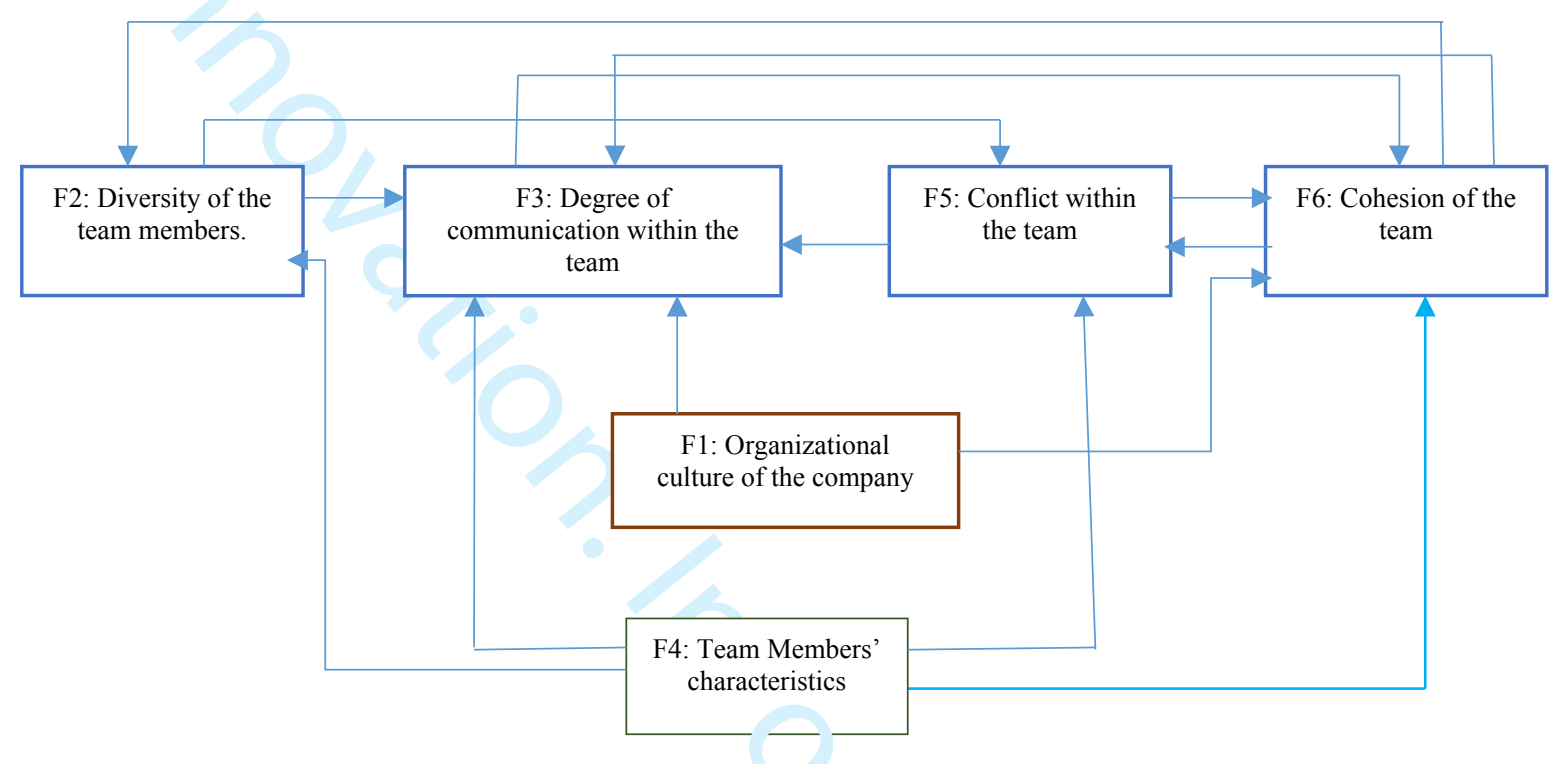

Figure 1: An ISM based model of factors to trust building in VPTs in construction sector of Middle East

Table 4 provides the entire summary of clusters and their characteristics. This technique demonstrated the systematic nature of the factors of trur. building of VPTs, encouraging the adoption of VPTs in construction companies. Therefore, the ISM trust model gave insights to project managers, Middle and Senior management about the structured relationships between the various factors of trust building in the VPTs. 
Table 4: Cluster and its characteristics

\begin{tabular}{|c|c|c|c|c|c|}
\hline $\begin{array}{l}\text { Cluster } \\
\text { No. }\end{array}$ & Clusters & Characteristics & $\begin{array}{l}\text { Driving } \\
\text { Power }\end{array}$ & $\begin{array}{c}\text { Dependence } \\
\text { Power }\end{array}$ & $\begin{array}{c}\text { Challenging } \\
\text { Factors }\end{array}$ \\
\hline $\mathrm{I}$ & $\overline{\text { Autonc inuts }}$ & $\begin{array}{l}\text { These issues are relatively } \\
\text { disconnected from the system, with } \\
\text { wh they have only few links, } \\
\text { wh may not be strong. }\end{array}$ & Weak & Weak & -- \\
\hline II & Dependent & $\begin{array}{l}\text { These issues are the automatic } \\
\text { followers of other issues. }\end{array}$ & Weak & Strong & $\mathrm{F} 2, \mathrm{~F} 3, \mathrm{~F} 5, \mathrm{~F} 6$ \\
\hline III & Linkage & $\begin{array}{l}\text { These issues are unstable in the } \\
\text { sense that any action on these } \\
\text { issues will affect others and } \\
\text { feedback on themselves. }\end{array}$ & Strong & Strong & F1 \\
\hline IV & Independent & $\begin{array}{l}\text { These issues are the key drivers for } \\
\text { implementation. Management has } \\
\text { to pay maximum attention to these } \\
\text { issues to get quick results. }\end{array}$ & Strong & Weak & F4 \\
\hline
\end{tabular}

\section{Discussion}

\section{ISM model}

The factors of trust building within VPTs in the construction sector of the Middle East pose substantial challenges for Project Managers, Middle management, and the Top management of the construction companies. The ISM model highlights the major factors of $\mathrm{i}$ ust and provides a means for analysing the interaction between these factors. These factors sre essential for the success of VPTs and contribute to increasing the productivity of the companie ;. T.1e ISM model shown in Figure 1 and the driver power-dependence diagram shown in Fig w $\boldsymbol{w}_{\mathbf{2}}$ provides valuable insights into the factors of building trust in VPTs, and their relative impurtance and interdependence. 
Lowest Level Factors and their Relationships: The ISM model shows that characteristics of team members (although specific measurements were not collected, these include ability, integrity, benevolence, competence, reliability and professionalism) are the most significant factors for building trust in virtual team members. This aligns with a previous study by Zuofa and Ochieng (2017), which revealed that a greater understanding of the various characteristics of specific team members is required for efficient VPT coordination. The team members' ability indicates the skills and competencies required for effective communication, affecting the team's communication structure. The integrity of the team members enables other team members to believe in each other. It is assumed that trustee would follow principles accepted by the trustor. The integrity of team members leads to cohesion as it greatly motivates the trust among the team members (Lewicki et al., 1998). However, the violation of integrity characteristics leads to conflict within the team (Turesky et al., 2020). Benevolence deals with interpersonal care, concern, and willingness to help others by keeping aside the egocentric profit motive. These characteristics help build up trust in the team, no matter how much diversity is there. As the virtual teams handle multiple tasks that are highly interdependent, the team me $n b_{i}$ characteristics help in information sharing. This greatly reduces the conflict among the team members helping the teams to achieve their goals. Therefore, the team members' characteristics play a great role in enhancing the communication and cohesion within the team and reducing the 0. lict irrespective of the team's diversity (Turesky et al., 2020). However, it does not have any 1 Jle co play in enhancing the organisational culture of the company. It does not affect the company': $c^{\prime}$ rnorate culture as team members' characteristics are inbuilt and occasionally change due to externa1 actors.

Middle-Level Factors and their Relationships: The organisational alture of the company consists of many elements such as clear objectives and goals, recruitmen ${ }^{1}$ str: tegy, rewards of the team members, fair policy of team evaluation, mentoring of the team members and degree of task interdependence. It stands at the second level of ISM hierarchy. If the team members are made clear of their objectives and goals at the beginning of creating virtual teams, this helps greatly achieve the organisation's goals (Morrison-Smith \& Ruiz, 2020). Goal setting improves the trust of the team members as it stretches the intensity and persistence of the team members by enabling them to channelise their behaviour towards improved work performance. It affects the communication within the team by acting as the motivational factor for the team members. At the 
same time, the companies need to be very focused while recruiting candidates for the VPTs. The selection criteria of an organisation affect the type of people that will be in teams. Failing to attain the right kind of people in the teams leads to conflicts later in the projects. The fair policy of team evaluation reduces the friction among the team members, thus building strong bonding within the team members. Whereas the team's relationship conflict spoils the company's organisational culture, the task-based conflict increases the creativity and productivity of the team. Therefore the organisational culture of the company increases the communication within the company and cohesion among the team members but gets affected by the relationship conflicts of the team members (Morrison-Smith \& Ruiz, 2020).

Top Level Factors and their Relationships: The diversity of the team members, communication among the team members, conflict within the team and cohesion of the team form the top level of the hierarchy. The factors at this level are dependent on other issues for their existence. The diversity of the team effects the communication of the team as the members belong to diverse cultures and the nature of communication differs from one culture to another. For example, the Japanese prefer detailed and thorough explan’ «ns for any issue, whereas Americans always prefer prompt replies. The diversity also affects the team's cohesion in a way that if the team is short-lived, the diverse culture negatively affects the cohesion of the team as there is no time to have bonding within the team. Communication positiv, y affects cohesion as the more the communication happens within the team; the more is the bonding within the team (Zuofa \& Ochieng, 2017). This results in better collaboration within the team, which is very much required as the teams are geographically dispersed. Effective communication, especially during the early stages of the team's development, plays a vital role in gaining and maintaining trust. The conflict within the team decreases the bonding between the team members and also results in less communication among the team members. This happens when the conflicts become relationship and personal based and their frequency increases with time. If the team is firmly knitted together, it will increase the team's communication, thus increasing the team's trust building, no matter how diverse the team is. The factors at this top-level do not exist on their own. They are being affected by the organisational culture and the characteristics of team members, as discussed in the middlelevel factors. 


\section{'MICMAC' Analysis}

The ISM model brings out the most important factors that affect trust building within the VPTs. The MICMAC principle is based on the multiplication of matrix to classify the key factors that drive the system in various categories. The objective of the MICMAC analysis is to analyse the driving power and the dependence of the variables (Faisal et al., 2006; Mandal, 1994). In this analysis, the factors that effects trust building in VPTs in the construction sector of the Middle East described earlier are classified into four clusters: (i) autonomous factors, (ii) dependent factors, (iii) linkage factors and (iv) independent factors. Subsequently, the driving powerdependence diagram is cr ststructed, as shown in Table 5.

Table 5: Driving Power- Dependence Diagram

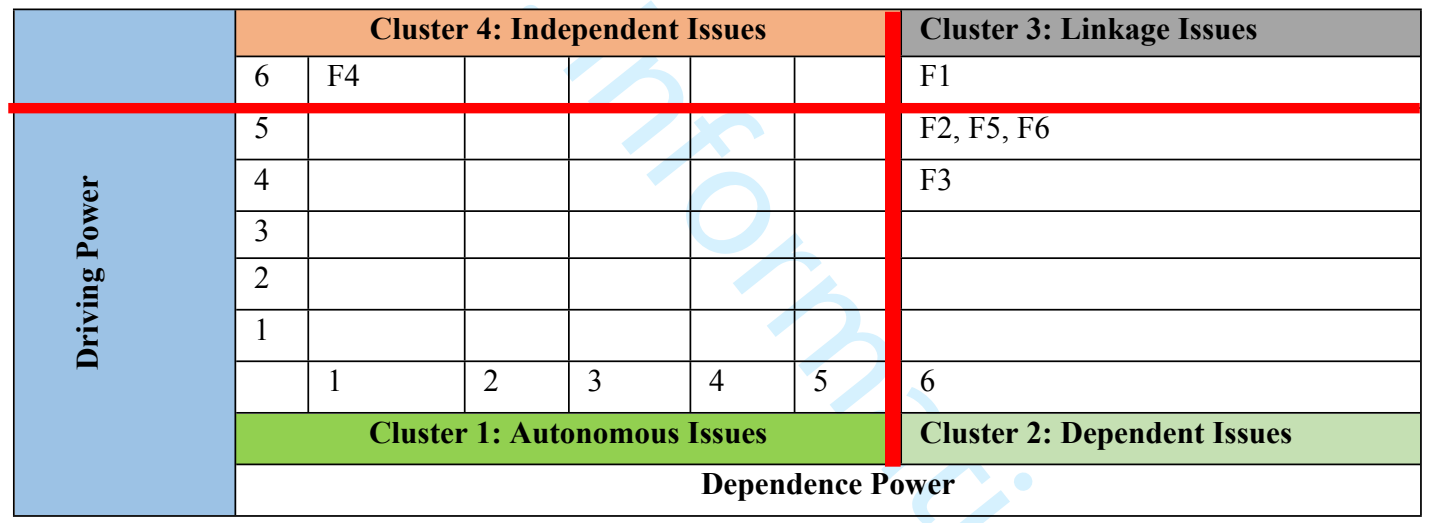

Autonomous cluster: The driving-dependence power diagram, as shown in Table 5 indicates that there are no autonomous factors in the trust building of VPTs. The absuree of any factor from the autonomous category shows that all the considered factors influence the tr- $-{ }^{+}$building of VPTs in the construction sector. Autonomous factors are weak driver power and uis veak dependence. The autonomous factors are relatively disconnected from the system, though tr $: \mathrm{y}$ have only few links, which may be strong. Hence, they do not have much influence on the system.

Dependent cluster: This is a dependent quadrant with low driving power and high deper if ace. They are seen at the top of the ISM hierarchy as shown in Figure 1, therefore considered as important factors. The management should tackle these factors by understanding the dependence of these factors on the lower level of the ISM. The results show that Diversity of the team 
members (F2), Degree of communication of the team (F3), conflict within the team (F5) and cohesion of the team (F6) are having weak driver power and strong dependence power. This means all these factors need to be addressed for trust building to be effective in VPTs. The team's diversity (F2) deals with both functional and cultural diversity of the team members. It gets affected by the characteristics of the team members and affects the communication within the team and cohesion of the team. The communication among the team members (F3) gets affected by the team members' characteristics, conflict within the team and the organisational culture of the company. The conflict within the team members (F5) gets affected by the characteristics of the team members as the violation of the integrity of team members' results in conflicts (Kildiushova, 2021). The conflict in the team is inversely proportional to the cohesion among the team members. The more closer a team is, the less is conflict between them. This is because the bonding among team members increases the understanding among the team members. The members who do not share information in the team greatly increase the conflict within the team. The cohesion of the team (F6) depends on the kind of conflict happening in the team. The task conflicts relate to differences referring to the tasks executions. This kind of conflict gets easily resolved in discussions yielding more productive outcomes. ${ }^{r} \cdot{ }^{\prime}$ hereas relationship conflicts are concerned with interpersonal incompatibilities and are typically associated with tension in the team. This relationship conflicts that decrease the cohesion between the team members as it involves ego in the team. It also gets affected by the team member characteristics, team diversity, and company organisational policies. The fair team evaluation and rewi $\mathrm{rd}$, tructure of organisations increases the trust of team members in the companies and builds strong bonding among the team members, enabling them to achieve their deadlines.

Linkage cluster: They have strong driving power and also have strong dependence. Any change occurring to these factors will affect others and also feedback on themselves. Hence, these factors are unstable in nature, which may affect the trust building in VPTs of the construction sector either positively or negatively. The organisational culture of the organisation (F1) falls into this cluster. It consists of many elements such as clear objectives and goals, recruitment strategy, rewards of the team members, a fair policy of team evaluation, mentoring of the team members and degree of task interdependence. It strongly affects the team's communication and cohesion as it acts as a motivational factor to them by having clear goals and a fair policy of team evaluation. 
It gets affected by the conflict within the team as the relational conflicts strongly disturbs the company's working culture.

Independent cluster: This is an independent quadrant that has strong driving power but weak dependence power. The factors in this cluster are treated as a "key enabler". This enabler is placed in the root level of ISM hierarchy as shown in Figure 1. Therefore, it can be anecdotal that management should work out strategies to facilitate these independent factors for successful trust building in the VPTs. These factors possessing higher driving power in the ISM need to be taken care of on a priority basis because few other dependent factors are affected by them. In this study, Team members' characteristics (F4) falls into this category. The team members' characteristics strongly affect the diversity, communication, conflict within the team, and cohesion of the team as it's the different characteristics of team members that decide the level of trust in the team. As the characteristics of the team members can never be manipulated, it does not have any dependence on any other factor. Thus, a project manager needs to understand the different abilities of team members to channelise them to strong trust building of the team members for better productivity in the company.

\section{Implications of ISM model of trust}

The study is associated with the changes required within the construction companies that are associated with the VPTs. The implications of ISM Model of tr ${ }_{\text {Ast }}$ yrovide some guidelines to help busy managers to understand the issues involved with the working of VPTs. This ISM model of trust addresses the main factors responsible for building trust ir th s VPTs, especially in the context of the Middle East. It also recognised the various relationships amnng the various factors of trust building in the Middle East. This largely gives an outline to the ${ }_{\uparrow}^{n}$ fert managers of the construction companies to adopt the guidelines and address the complex 1:so of trust among VPTs for enhancing the performance of the VPTs.

The characteristics of the team members play a great role in the building of trust in the VPTr. ihe project managers are required to make the teams so that the members have ability, integrity, competence, reliability, and professionalism. This is the first and most valuable step in creating VPTs as the team member characteristics greatly impact the degree of communication, helps in 
reducing the conflicts within the team, and increase bonding among the team members. Since the members of the teams are from diverse cultures, it becomes more important for the project managers to have team members with the required characteristics so that the trust among the team members remains intact and helps increase the team's performance. The senior management of the construction companies is required to see that each member of the team is aware of the objectives and goals of the VPTs. If the team members are not clear about what is expected from them, it is challenging for the teams to achieve their goals.

Construction organisations also require a strong policy towards the recruitment of the right kind of people for the projects. The selection criteria of the company greatly affect the kind of people in the teams. The management also needs to have a fair policy of team evaluation. Since the VPTs are geographically dispersed, the management's role is to ensure they do not feel left out. It is always believed by the team members, as understood from the literature also, that the teams stationed at the head office get more priority as their work gets noticed clearly. The project managers are required to focus on the mentoring of the teams during the initial phases of the team creation. This is primarily because the teams are from diverse cultures, and the communication among the team members gets greatly affected by the diversity of the team members. So the initial kick-off meetings are of great help to resolve preliminary issues of team building. Since the VPTs are at different locations and are dispersed in nature, middle-level management must provide teams with the right kind of tools for communication. They need to see that the teams get the latest technology software with respect to engineering and design. The management needs to have team building exercises within the teams to break the ice among the members of the teams. The teams should be provided with training on conflict management, improving interpersonal and management skills. The team members should be sent to these kinds of training from one location to another so that it helps build confidence in other members of the dispersed teams and builds trust among them. This largely allows them to share information with each other for the execution of various projects.

\section{Conclusion}

This study presents the results of focus group discussion using ISM to develop a hierarchy of trust building factors in the VPTs. The six factors identified include; diversity of the team members, 
degree of communication within the team, conflict within the team, cohesion of the team, organisational culture of the company, and team members' characteristics. These factors have significant overlaps and relationships that are sometimes difficult to appreciate. The findings revealed that these factors are highly interlinked, therefore it was essential to structure the relationships. Hence, we applied ISM process to the data collected via a focus group on relationships between trust factors. Trust factors were classified based on their driving and dependence power using indirect relationship MICMAC analysis. The proposed model provides a useful tool for project managers of VPTs of the construction sector to focus on the most important factors for building trust among teams, thereby enhancing the team's productivity. Understanding the factors and their relationships will help construction companies of the Middle East address the major issues of trust building or at least understand and plan for them if they see distrust among the team members affecting their performance.

There are two possible limitations to this study. The first limitation is the study's scope, which is intentionally restricted to the context of trust factors in VPTs in the Middle East construction

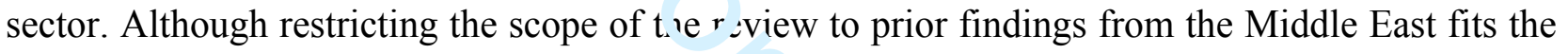
study's aim, it cannot be overlooked that the results cannot be freely generalised to other research contexts. The study's second limitation is related to an aspect of ISM methodology. Although ISM allows researchers to build the relationship between multiple causes of a certain phenomenon by offering a single systemic framework, it is relatively limited in statistically validating a hypothetical framework. The use of ISM in this study achieved the research goal of finding the precedence relationships among the major determinants of trust development in construction VPTs. Using structural equation modelling and a cross-sectional survey technique to explore the significance of relationships among the influencing factors of trust in VPTs, on the other hand, might be an intriguing area of future study. This would supplement the MICMAC analysis to strengthen further knowledge of significant relationships that require the most attention.

\section{References}

Ahuja, J. (2017). Modelling the Success Factors of Virtual Team. Indian Journal of Science and Technology, 9(48), 1-9.

Ahuja, M. K., \& Carley, K. M. (1999). Network structure in virtual organisations. Organisation science, 10(6), 741-757. 
Brewer, P. E. (2015). International Virtual Teams, Engineering Global Success. New Jersey: IEEE Press.

Bond-Barnard, T. J., Fletcher, L., \& Steyn, H. (2018). Linking trust and collaboration in project teams to project management success. International Journal of Managing Projects in Business, 11(2), 432-457.

Breuer, C., Hüffmeier, J., Hibben, F., \& Hertel, G. (2020). Trust in teams: A taxonomy of perceived trustworthiness factors and risk-taking behaviors in face-to-face and virtual teams. Human Relations, 73(1), 3-34.

Choi, O. K., \& Cho, E. (2019). The mechanism of trust affecting collaboration in virtual teams and the moderating roles of the culture of autonomy and task complexity. Computers in Human Behavior, 91, 305-315.

Crampton, C. D. (2001). The mutual knowledge problem and its consequences for dispersed collaboration. Organisation Science, 12, 356-371.

Cummings, J. N. (2004). Work groups, structural diversity, and knowledge sharing in a global organisation. Management Science, 50, 352-364.

Cunningham, J., \& MacGregor, J. (2000). Trust and the design of work: Complementary constructs in satisfaction and performance. Human Relations, 53, 1575-1591.

Davidavičienè, V., Al Majzoub, K., \& Meidute-Kavaliauskiene, I. (2020). Factors affecting knowledge sharing in virtual teams. Sustainability, 12(17), 6917.

Delizonna, L. (2017). High-Performing Teams Need Psychological Safety. Here's How to Create It. Retrieved January 16, 2021, from https://hbr.org/2017/08/high-performing-teams-needpsychological-safety-heres-how-to-create-it?referral $=03759 \& \mathrm{~cm}$ vc $=\mathrm{rr}$ item page.bottom

Evaristo, R. (2003). The management of distributed projects across cultures. Journal of Global Information Management, 11(4), 58-70.

Garro-Abarca, V., Palos-Sanchez, P., \& Aguayo-Camacho, M. (2021). Virtual Teams in Times of Pandemic: Factors That Influence Performance. Frontiers in Psychology, 12, 232.

George, J. P., \& Pramod, V. R. (2014). An Interpretive Structural Model ( ISM ) Analysis Approach In Steel Re Rolling Mills ( Srrms ). ' ternational Journal Of Research In Engineering And Technology, 2(4), 161-174.

Hacker, J. V., Johnson, M., Saunders, C., \& Thayer, A. L. (n19). Trust in virtual teams: A multidisciplinary review and integration. Australasian Journ .l of Information Systems, 23, 136.

Hosseini, M. R \& Chileshe, N. (2013), Global Virtual Engineerir。Te .ms (GVETs): A fertile ground for research in Australian construction projects context, 'nternational Journal of Project Management, 31 (8), 1101-1117.

Hosseini, M. R., Chileshe, N., Baroudi, B., Zuo, J., \& Mills, A. (‘01'). Factors affecting perceived level of virtuality in hybrid construction project teams $\left(\mathrm{H}^{\prime}, \mathrm{P}_{\mathrm{s}}\right)$ ): A qualitative study. Construction Innovation, 16(4), 460-482.

Hulnick, G. (2000). "Doing Business Virtually," Communication World, 17(3), 33-36.

Jarvenpaa, S. L., Knoll, K., \& Leidner, D. E. (1998). Is Anybody Out There? Antecedents of Trust in Global Virtual Teams. Journal of Management Information Systems, 14(4), 29-64.

Kaur, S. (2017). Model for assessment of trust within VPTs of construction sector in the Middle East (Doctoral dissertation, University of Salford).

Kaur, S., Akre, V., \& Arif, M. (2019, November). SMART project management for SMART cities: Analysing critical factors affecting trust among VPTs. In 2019 Sixth HCT Information Technology Trends (ITT) (pp. 65-72). IEEE. 
Kildiushova, T. (2021). Building trust in virtual teams. (Doctoral dissertation, Universität Linz). https://epub.jku.at/obvulihs/content/titleinfo/6021967

Kimble, C. (2011). Building effective virtual teams: How to overcome the problems of trust and identity in virtual teams. Global Business and Organizational Excellence, 30(2), 6-15.

Lewicki, R. J., McAllister, D. J., \& Bies, R. J. (1998). Trust and distrust: New relationships and realities. Academy of management Review, 23(3), 438-458.

$\mathrm{Lu}, \mathrm{L}$. (2015). Building trust and cohesion in virtual teams: the developmental approach. Journal of organisational effectiveness: People and performance. 2(1), 55-72.

Lukić, J. (2014). The role of information and communication technology in a virtual organisation: challenges for virtual employees, 1st International Academic Conference places and technologies (pp. 1098-1105), Belgrade: Faculty of Architecture.

Lukić, J. M., \& Vračar, M. M. (2018). Building and nurturing trust among members in VPTs. Strategic Management-International Journal of Strategic Management and Decision Support Systems in Strategic Management, 23(3).

Luo, J., Van de Ven, A., Jing, R., \& Jiang Y. (2018). Transitioning from a hierarchical product organisation to an open platform organisation: a Chinese case study. Journal of Organization Design, 7 (1), 1-14.

Morrison-Smith, S., \& Ruiz, J. (2020). Challenges and barriers in virtual teams: a literature review. SN Applied Sciences, 2, 1-33.

Obi, L., Awuzie, B., Obi, C., Omotayo, T. S., Oke, A., \& Osobajo, O. (2021). BIM for Deconstruction: An Interpretive Structural Model of Factors Influencing Implementation. Buildings, 11(6), 227.

Pangil, F., \& Chan, J. M. (2014). The mediating effect of knowledge sharing on the relationship between trust and virtual team effectiveness. Journal of Knowledge Management, 18(1), 92106.

Paul, D. L., \& McDaniel Jr, R. R. (2004). A field ¿tv dy of the effect of interpersonal trust on virtual collaborative relationship performance. Mi.s c arterly, 183-227.

Piccoli, G., Powell, A., \& Ives, B. (2004). Virtual tear s: 'um control structure, work processes, and team effectiveness. Information Technology \& Pec ple. 27(4), 359-372.

Ravi, V. and Shankar, Ravi, (2005). Analysis of interaciur, among the barriers of reverse logistics. Technological Forecasting \& Social Change, 7'(8) pp1011-1029.

Rutz, L., \& Tanner, M. (2016). August. Factors that influence performarse in global virtual teams in outsourced software development projects. In 2016 IEEE iter zational Conference on Emerging Technologies and Innovative Business Practices for the Tr' nsformation of Societies (EmergiTech) (pp. 329-335). IEEE.

Schiller, S. Z., Mennecke, B. E., Nah, F. F., \& Luse, A. (2014). Institutic na' ooundaries and trust of virtual teams in collaborative design: An experimental study in a virtual world environment. Computers in Human Behavior, 35, 565-577.

Staples, D., \& Ratnasingham, P. (1998). Trust: the panacea of virtual manas:mf it? ICIS '98 Proceedings of the International Conference on Information Systems, 128-14

Tannenbaum, S. I., Mathieu, J. E., Salas, E., \& Cohen, D. (2012). Teams Are Cinging: Are Research and Practice Evolving Fast Enough? Industrial and Organisational Psycholoc, ${ }_{y}, 5$, $2-24$.

Taras, V., Tullar, W. L., Liu, Y., \& Pierce, J. R. (2018). Straight from the horse's mouth: Justifications and prevention strategies provided by free riders on global virtual teams. Journal of Management and Training for Industries, 5(3), 51-67. 
Turesky, E. F., Smith, C. D., \& Turesky, T. K. (2020). A call to action for virtual team leaders: practitioner perspectives on trust, conflict and the need for organisational support. Organisation Management Journal, 17(4/5), 185-206.

Vakola, M., \& Wilson, I. (2004). The challenge of virtual organisation: critical success factors in dealing with constant change. Team Performance Management, 10(5/6), 112-120.

Vinaja, R. (2003). Major challenges in multi-cultural virtual teams. 33 ${ }^{\text {rd }}$ Annual Conference of the Decision Sciences Institute Southwest Region, Houston, TX, 78541(956), 341-346.

Warfield J.W., (1974). Developing interconnected matrices in structural modelling, IEEE Transactions on Systems Men and Cybernetics, 4(1), 51-81.

Warkentin, M., Sayeed, L., \& Hightower, R. (1997). Virtual Teams versus Face-to-Face Teams: An Exploratory Study of a Web-based Conference System. Decision Sciences, 28(4), 975996.

Whillans, A., Perlow, L., \& Turek, A. (2021). Experimenting during the shift to virtual team work: Learnings from how teams adapted their activities during the COVID-19 pandemic. Information and Organization, 31(1), 100343.

Zimmermann, A. (2011). Interpersonal relationships in transnational, virtual teams: towards a configurational perspective. International Journal of Management Reviews, 13(1), 59-78.

Zuofa, T., \& Ochieng, E. G. (2021). Investigating Barriers to Project Delivery using Virtual Teams. Procedia Computer Scie' ce, 181, 1083-1088. 